\title{
Lectura de las desigualdades en la Zona Metropolitana del Valle de México a partir de los precios inmobiliarios
}

Read the Inequalities in the Metropolitan Area of Mexico-City Using Real Estate Prices

Leitura das desigualdades na Zona Metropolitana do Vale do México baseada nos preços de imóveis

Antonine Ribardière* Jean-François Valette ${ }^{* *}$

Recibido: 2 de agosto del 2019

Aprobado: 4 de abril del 2020

https://doi.org/10.12804/revistas.urosario.edu.co/territorios/a.8153

Para citar este artículo:

Ribardière, A., \& Valette, J. F. (2021). Lectura de las desigualdades en la Zona Metropolitana del Valle de México a partir de los precios inmobiliarios. Territorios, (44), 57-84. https://doi.org/10.12804/revistas. urosario.edu.co/territorios/a.8153

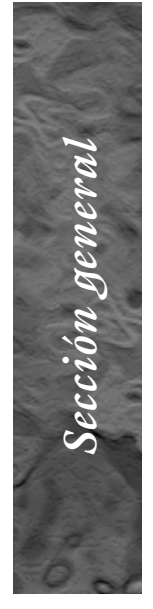

\footnotetext{
* Universidad Paris 1 Panthéon-Sorbonne. Laboratorio UMR 8586 PRODIG. Correo electrónico: antonine.ribardiere@ univ-parisl.fr. ORCID: bttp://orcid.org/00000002-8209-7007

** Universidad Paris 8 Vincennes-Saint-Denis. Laboratorio UMR 7533 LADrSs, asociado al Laboratorio UMR 8586 PRODIG. Correo electrónico: jean-francois.valette02@ univ-paris8.fr. ORCID: bttp://orcid.org/00000002-4023-0586
} 
Palabras clave

Anuncios inmobiliarios; desigualdad urbana; mercado de la vivienda; Zona Metropolitana de México.

Keywords

Real estate

advertisements; urban inequalities; housing market; Mexico City Metropolitan Area.

Palavras-chave Zona Metropolitana do México; anúncios imobiliários; desigualdade urbana; mercado da habitação.

territarias 44

\section{RESUMEN}

Este artículo presenta diferentes lecturas producto del cruce de tres fuentes de información sobre el mercado de la vivienda en la Zona Metropolitana del Valle de México: anuncios de ventas y de alquiler en línea, anuncios en periódicos y anuncios en el espacio público. Por un lado, a la altura de la metrópoli fue posible ubicar los anuncios en línea al nivel de las unidades espaciales censales y al de los diferentes "tipos de poblamiento". Por otro, el enfoque empírico permitió una mejor comprensión de la producción y la oferta inmobiliaria habitacional. Primero, es posible mostrar la diferencia de visibilidad y legibilidad de la ciudad según el canal de información. Segundo, la variabilidad espacial de los precios anunciados refleja las tensiones que existen en el espacio habitacional a diferentes escalas y, permite una lectura de la división socio-espacial y de la segmentación del mercado de la vivienda, destacando la reproducción de desigualdades.

\section{ABSTRACT}

The purpose of this article is to present different readings allowed by the cross-referencing of three sources of information on the housing market in the Metropolitan Area of Mexico-City: online sales and rental advertisements, ads in newspapers and ads in public space. On the one hand, at the level of the metropolis, it was possible to locate the online ads at the level of census spatial units and at the level of the different "types of settlement". On the other hand, the empirical approach allows a better understanding of housing real estate production and supply. First, it is possible to show the differences in visibility and readability of the city according to the channel of information on the real estate market. Second, the spatial variability of advertised prices reflects the tensions that run through the metropolis, at different geographical levels, and allows a reading of the socio-spatial division and the segmentation of the housing market, highlighting the reproduction of inequalities.

\section{RESUMO}

Este artigo apresenta diferentes leituras permitidas a partir do cruzamento de três fontes de informação sobre o mercado de imóveis na Zona Metropolitana do Vale do México: anúncios de vendas e aluguéis on-line, anúncios em jornais e anúncios em espaços públicos. Por um lado, a nível de metrópole foi possível correlacionar os anúncios on-line a nível de unidades espaciais censitárias e a nível dos diferentes "tipos de povoamento". Por outro lado, o enfoque empírico permite uma melhor compreensão da produção e oferta imobiliária habitacional, além da diferença de visibiliddae e legibilidade da cidade conforme o canal de informação. A variabilidade espacial dos preços anunciados reflete as tensões existentes no âmbito habitacional, em diferentes escalas, e permite uma leitura da divisão socioespacial e da segmentação do mercado habitacional, destacando a reprodução de desigualdades. 


\section{Introducción}

Las fuertes tensiones que existen sobre el mercado de la vivienda, necesitan disponer de herramientas para seguir los indicadores de los valores inmobiliarios. ¿Cuánto vale una vivienda en la Zona Metropolitana del Valle de México?' Según el Global Property Guide ${ }^{2}$ para un departamento de $120 \mathrm{~m}^{2}$, cuesta aproximadamente 6,5 millones de pesos mexicanos. Para la Sociedad Hipotecaria Federal (SHF), es de 1 millón de pesos en la Ciudad de México (CDMX) y de 500000 pesos en el Estado de México. ${ }^{3}$ Los rangos de precios son enormes y reflejan las desigualdades en la metrópoli; a su vez, permiten visualizar la diversidad de los sistemas de producción de vivienda y la necesidad de tomar en cuenta una gran variedad de fuentes para entenderlos.

Este artículo ${ }^{4}$ presenta diferentes lecturas posibles a través del cruce de tres fuentes de información sobre el mercado de la vivienda en la ciudad: los anuncios de ventas y de alquiler en línea, los anuncios en periódicos y los anuncios en el espacio público. El análisis y la confrontación de bases de datos y encuestas empíricas, permitieron hacer una lectura global de la división socio-espacial y la segmentación del mercado de la vivienda, destacando la reproducción de las desigualdades sociales en el espacio urbano.

Como parte de un proyecto de investigación franco-mexicano, ${ }^{5}$ se trabajó sobre la constitución de bases de datos de acuerdo con los precios inmobiliarios en la Zona Metropolitana del Valle de México (ZMvM). ${ }^{6}$ Se trató, por una parte, de desarrollar un indicador para complementar los otros indicadores socioeconómicos clásicos, con el objetivo de caracterizar de forma sistemática los contextos residenciales en México. Por otra parte, se intentó utilizar los precios inmobiliarios para registrar las desigualdades sociales en una ciudad como la Zona Metropolitana de México, que está atravesada por múltiples segmentaciones. En la ZMVM existe un contexto bien conocido en América Latina, el cual está caracterizado por la coexistencia de un mercado formal y de uno informal (Abramo, 2003; Streule et al., 2020), el mismo que se refiere más frecuentemente - pero no únicamente- a tierras con el régimen de propiedad "social", aquellas que, desde su origen, no están destinadas al desarrollo urbano y sobre las que, sin embargo, sigue extendiéndose la mancha urbana. ¿Entonces, cómo se puede abordar el tema de los valores inmobiliarios de la vivienda? ¿Cuáles son los desafíos de un trabajo sobre este tema?

Los recientes trabajos académicos sobre este tema, ponen en evidencia las transformaciones de la producción inmobiliaria como consecuencia (i) de las inversiones masivas de capitales nacionales e internacionales en el sector inmobiliario y, (ii) del crecimiento del endeudamiento de los hogares, cuyas estrategias y prácticas están involucradas en el proceso de
${ }^{1}$ La ZMVM está constituida por 16 demarcaciones territoriales de la Ciudad de México, 59 municipios del Estado de México y 1 en el Estado de Hidalgo.

${ }^{2}$ Precios indicados en noviembre del 2015.

3 Institución que ba sustituido al Banco Nacional de México desde el 2001 para las operaciones relacionadas con la construcción, adquisición y mejoramiento de la vivienda, en particular, las politicas de acceso a la vivienda de interés social. El valor mostrado corresponde al último trimestre del 2014.

${ }^{4}$ Este trabajo ha contado con el apoyo financiero del LabEx DynamiTe (ANR-11-LABX-0046) en el marco del programa "Investissement d'avenir".

5 Entre investigadores de la FLACSO México y las Universidades Paris 1 y Paris-Diderot. Este programa se dedicaba al estudio de los recursos urbanos y las trayectorias familiares en México (PICS RESUM). Los primeros resultados fueron presentados en Ribardière $y$ Valette (2017a) y, en octubre del 2018, se presentó una ponencia en el Seminario Internacional $\Longrightarrow$

\section{territarias 44}


$\Leftarrow$

del Consejo Latinoamericano de Ciencias Sociales (CLACSO), "Nuevas desigualdades urbanas en América Latina: conflictos, resistencias, fronteras y actores" (Santiago de Chile). Agradecemos aqui, a Kevin Bain, por su ayuda con la redacción en español del presente texto.

${ }^{6}$ Sobre este tema, véase Libertun y Guerrero (2017).

\section{tersitarias 44}

financiarización de las economías y de las sociedades urbanas (Aveline-Dubach, 2008; Cetre, 2015; Cuervo, 2017; Girón \& Chapoy, 2009; David \& Halbert, 2013; Delgadillo, 2016a; Isunza Vizuet \& Méndez Bahena, 2011; Le Goix et al., 2016; de Mattos, 2016). Las consecuencias son las siguientes: primero, una inestabilidad cada vez mayor de los mercados inmobiliarios, y un alto nivel de especulación; y segundo, una estandarización de las producciones urbanas, como los condominios o los conjuntos de interés social, cualquiera sea el nombre del programa que le acompañe en un contexto nacional específico, por ejemplo, Minha Casa en Brasil, los Programas Sectoriales de Vivienda de la década del 2000 en México, entre otros.

En el territorio metropolitano dichas tendencias se suscitan en las periferias, como son los conjuntos urbanos de vivienda de interés social, construidos sobre antiguos ejidos del Estado de México, los cuales han sido transformados y convertidos directamente en liquidez de los bancos asociados con grupos inmobiliarios. De igual manera, existe la financiarización a través de los proyectos comerciales o de vivienda que toman lugar en el centro y pericentro, mismos que participan en el proceso de densificación de la Ciudad de México. ${ }^{6}$

En ese orden de ideas, la hipótesis de este texto es que diferentes precios significan distintos bienes raíces, pero también variados contextos locales, y entonces, varias posibilidades de reproducción de la división socio-espacial, teniendo en cuenta el hecho de que los procesos de renta de la tierra - como los de valorización inmobiliaria-, no se inscriben de manera homogénea en el espacio habitacional. Entonces, las preguntas que guían la discusión son: ¿¿De qué manera los precios inmobiliarios permiten entender la heterogeneidad de los contextos habitacionales? ¿Cómo estudiarlos? ¿Con qué tipo de datos para hacer un estudio sistemático? Este problema metodológico se cuenta para todos los investigadores que trabajan sobre el tema, en general, tanto en México como en América Latina y también en Estados Unidos como en Francia (Casanova et al., 2017; Le Goix \& Vesselinov, 2013).

Después de la discusión metodológica, se verá cómo los anuncios inmobiliarios implican una diferencia de visibilidad y legibilidad de la ciudad, según el canal de información y una sobrerrepresentación de los bienes caros. Más adelante, se analizará en particular la variabilidad espacial de los precios anunciados, y para finalizar, se cuestionará la amplia heterogeneidad socio-espacial de los espacios calificados como "populares".

\section{Discusión metodológica}

En México el análisis de los precios de la vivienda ya ha sido investigado. Terrazas (1996) y Perló y Kunz (1994), realizaron los primeros estudios importantes sobre el mercado de bienes raíces residenciales,

ANTONine Ribardière, JeAn-FranÇOIS VALETte 
relacionados con el tema del acceso al suelo urbano. Estos autores hicieron un diagnóstico de los mecanismos de producción, financiamiento, regulación y políticas de la vivienda (Perló \& Kunz, 1994; Perló, 2002). Más adelante, a finales de la década de los noventa, se llevó a cabo una primera identificación sistemática de los diversos segmentos $^{7}$ del mercado de bienes raíces residenciales, basándose en anuncios publicados en periódicos, sobre una muestra obtenida de colonias y diversas series de encuestas empíricas (Kunz et al., 2001). Se destacó la variedad de segmentos del mercado, pero también su porosidad, en especial, en las colonias populares donde el proceso de consolidación puede llegar a permitir la integración en la esfera formal de un bien construido de manera informal. ${ }^{8}$

Otro enfoque de los precios de bienes raíces - desde un punto de vista más económico-, es el modelo hedónico, la “explicación” estadística de los precios por las características intrínsecas del bien - relacionadas con su ubicación y su entorno-, y por los servicios dados por este. El anterior enfoque ha permitido primero, identificar submercados al nivel de la metrópoli (Sobrino, 2014); segundo, resaltar la valorización en las partes céntricas causada por la producción nueva y su estrecha relación con la dinámica de densificación (Valdivia, 2014); y tercero, estimar los costos sociales y económicos producidos por el alejamiento entre las zonas de vivienda y de empleo, en relación con la expansión urbana bajo la forma de conjuntos urbanos periféricos (Lara et al., 2017).

En suma, los precios del suelo y de los bienes raíces fueron utilizados en el análisis de procesos socio-espaciales complejos, como en los estudios sobre el cierre del espacio residencial, la pobreza (Eibenschutz \& Benlliure, 2009), o mejor dicho, el acceso a la vivienda de las personas de bajos recursos (Azuela \& Tomas, 1997; Iracheta \& Medina, 2008). El tema de los mercados de la vivienda popular, ha sido objeto de investigaciones específicas en colonias populares de México, como en otros países de América Latina (Abramo, 2008, 2009; Cravino, 2008; Jaramillo, 2008; Parias Durán, 2008; Jaramillo \& Cuervo, 2014), sucediendo de igual manera con el mercado de la vivienda de interés social (Delgadillo, 2016b; Lara et al., 2017; Libertun, 2018; Schteingart, 1989).

Específicamente en cuanto a los sectores populares, estos análisis de los mercados de tierras y bienes raíces en la Ciudad de México, Bogotá, Río de Janeiro y Buenos Aires, han permitido nutrir la comprensión de los principales patrones de desigualdad urbana, teniendo en cuenta el análisis de la movilidad residencial de los hogares en esas zonas. Esos trabajos identificaron submercados informales diferenciados según un gradiente de consolidación, entre loteamientos — con situaciones oligopólicas - y asentamientos consolidados -impulsados por la lógica mercantil-, y en cuanto a la relación
Se puede entender por "segmento" a una parte especifica del mercado inmobiliario, resultado de procesos de diferenciación $y$ de jerarquización de las características del bien raiz - aunque estos procesos no se basen en criterios bien definidos-.

${ }^{8}$ Véase las demostraciones de Azuela y Tomas (1997), Connolly (2008) y Ward et al. (2015).

territarias 44 
9 Para más detalles sobre la metodología en cuanto a los anuncios en línea, véase Ribardière y Valette (2017a).

${ }^{10}$ Queremos agradecer a la empresa Metros Cúbicos por su ayuda, en particular, a Simon Dalgleish. Estos anuncios fueron consultados durante el mes de julio del 2014.

${ }^{11}$ Se obtuvo la información del sitio mediante un programa informático de automatización de apertura de las páginas web $y$ de registro de precios. Agradecemos a François Lelay por su asistencia $y$ experiencia durante la fase de recopilación de información. Estos anunciosfueron consultados $d u$ rante un dia de octubre del 2014.

12 Estas bases de datos fueron compiladas manualmente. El Universal se consultó entre el 28 de noviembre hasta el 5 de diciembre del $2014 y$ Encuentra tu casa desde el 27 de noviembre hasta el 17 de diciembre del 2014.

${ }^{13}$ Se realizaron entrevistas a habitantes entre el 2009 y el 2018, en especial, a lideres y propietarios de parcelas, quienes conocen los precios aproximados usados por los vendedores en las zonas.

\section{territarios 44}

entre oferta y demanda, la asimetría de la información, la homogeneidad o la heterogeneidad del producto, las externalidades - exógenas y endógenas - y la racionalidad de los agentes (Abramo, 2008). En general, el mercado residencial informal es el resultado de la dificultad y la incapacidad de integrar una gran parte de la sociedad urbana en el mercado formal, reproduciendo así las desigualdades anteriores. Las políticas formales de vivienda han sido y siguen siendo ineficaces para satisfacer las demandas de todas las categorías populares: participan en la reproducción de la exclusión de las personas en situación de pobreza y de las políticas de subsidios para la vivienda popular (Abramo, 2009; Parias Durán, 2008). Sin embargo, los sectores populares informales no están exentos de la lógica capitalista. Por una parte, unas características no salen del propio sistema capitalista: la lentitud de la producción inicial y la gran cantidad de trabajo social consumido (HiernauxNicolas, 1991; Jaramillo, 2008), lo que da lugar a un bien durable con muchos valores, caracterizado por un consumo progresivo y un largo periodo de circulación en el mercado (Jaramillo \& Cuervo, 2014). Por otra parte, el mercado de alquiler informal desempeña una función estructuradora en el proceso de densificación y valorización de los sectores populares (Coulomb, 1988; Parias Durán, 2008; Abramo, 2009; Ward et al., 2015). El análisis de la formación de los precios revela, entre otras cosas, la importancia del estado de consolidación de los inmuebles, el peso del valor del suelo, el papel del contexto y la ubicación -factor externo social y simbólico-, la flexibilidad de construcción - libertad urbanística-, la importancia de las lógicas sociales locales de reciprocidad, pero también la importancia del margen de negociación de los precios. En el caso del mercado residencial de los sectores informales, se confirma las dimensiones clásicas de su organización: el peso de las redes sociales y las organizaciones políticas locales, combinadas con los juegos de reciprocidad familiar que permiten comprender la estructuración de las solidaridades, como también los conflictos que animan estos mercados (Cravino, 2008).

De modo que, el primer objetivo de este artículo es hacer un inventario de las fuentes disponibles y accesibles sobre la cuestión de los precios inmobiliarios, para con ello efectuar un diagnóstico de su fiabilidad. Se trabajó con siete bases de datos construidas en el 2014 (tabla 1). Tres de anuncios en línea: ${ }^{9}$ la primera, sobre las ventas, la cual nos fue proporcionada gracias a un convenio celebrado con el anunciante Metros Cúbicos, ${ }^{10} \mathrm{y}$ dos, a partir del sitio Realtor.com. ${ }^{11}$ Así mismo, cuatro bases de anuncios impresos de venta y renta, publicados en El Universal y en Encuentra tu casa. ${ }^{12}$ Además, un trabajo de terreno empírico en colonias de la periferia permitió obtener una aproximación de los precios de los bienes anunciados por otros canales. ${ }^{13}$

ANTONINE Ribardière, JEAN-FranÇOIS VALETTE 
Tabla 1. Número de anuncios inmobiliarios registrados y cobertura espacial de la ZMVM en el 2014

\begin{tabular}{|c|c|c|c|c|c|c|}
\hline \multirow[b]{2}{*}{ Canal } & & \multirow{2}{*}{$\begin{array}{l}\text { Número de } \\
\text { registros } \\
\text { (después de } \\
\text { la limpieza) }\end{array}$} & \multirow{2}{*}{$\begin{array}{l}\text { Fecha de } \\
\text { los datos }\end{array}$} & \multicolumn{3}{|c|}{ Número de unidades con datos* } \\
\hline & & & & $\begin{array}{l}\text { Municipio } \\
(76)\end{array}$ & $\begin{array}{l}\text { Colonia } \\
(6274)\end{array}$ & $\begin{array}{c}\text { AGEB } \\
(5666)\end{array}$ \\
\hline \multirow{3}{*}{ Internet } & $\begin{array}{l}\text { Metros } \\
\text { Cúbicos- } \\
\text { venta }\end{array}$ & 18015 & $\begin{array}{l}\text { julio del } 2014 \\
\quad(1 \mathrm{mes})\end{array}$ & $\begin{array}{c}55 \\
(=3 / 4)\end{array}$ & $\begin{array}{c}1716 \\
(=27,4 \%)\end{array}$ & $\begin{array}{c}2230 \\
(=39,4 \%)\end{array}$ \\
\hline & $\begin{array}{l}\text { Realtor } \\
\text {-venta }\end{array}$ & 2387 & $\begin{array}{c}\text { octubre del } \\
2014 \\
\text { (1 día) }\end{array}$ & $\begin{array}{c}54 \\
(=7 / 10)\end{array}$ & $\begin{array}{c}802 \\
(=12,8 \%)\end{array}$ & $\begin{array}{c}\text { Precisión } \\
\text { insuficiente }\end{array}$ \\
\hline & $\begin{array}{l}\text { Realtor- } \\
\text { renta }\end{array}$ & 545 & $\begin{array}{l}\text { octubre del } \\
2014 \\
\text { (1 día })\end{array}$ & $\begin{array}{c}32 \\
(=2 / 5)\end{array}$ & $\begin{array}{c}261 \\
(=4 \%)\end{array}$ & $\begin{array}{c}\text { Precisión } \\
\text { insuficiente }\end{array}$ \\
\hline \multirow{4}{*}{$\begin{array}{l}\text { Periódico } \\
\text { impreso }\end{array}$} & $\begin{array}{c}\text { El } \\
\text { Universal- } \\
\text { venta }\end{array}$ & 289 & $\begin{array}{c}\text { noviembre/ } \\
\text { diciembre del } \\
2014 \\
(3 \text { semanas })\end{array}$ & $\begin{array}{c}32 \\
(=2 / 5)\end{array}$ & $\begin{array}{c}173 \\
(=3 \%)\end{array}$ & $\begin{array}{c}\text { Precisión } \\
\text { insuficiente }\end{array}$ \\
\hline & $\begin{array}{c}\text { Encuentra } \\
\text { tu casa- } \\
\text { venta }\end{array}$ & 1048 & $\begin{array}{c}\text { noviembre/ } \\
\text { diciembre del } \\
2014 \\
\text { (3 semanas) }\end{array}$ & $\begin{array}{c}40 \\
(=1 / 2)\end{array}$ & $\begin{array}{c}432 \\
(=7 \%)\end{array}$ & $\begin{array}{c}\text { Precisión } \\
\text { insuficiente }\end{array}$ \\
\hline & $\begin{array}{c}\text { El } \\
\text { Universal- } \\
\text { renta }\end{array}$ & 451 & $\begin{array}{c}\text { noviembre/ } \\
\text { diciembre del } \\
2014 \\
\text { (3 semanas) }\end{array}$ & $\begin{array}{c}20 \\
(=1 / 4)\end{array}$ & $\begin{array}{c}204 \\
(=3 \%)\end{array}$ & $\begin{array}{c}\text { Precisión } \\
\text { insuficiente }\end{array}$ \\
\hline & $\begin{array}{c}\text { Encuentra } \\
\text { tu casa- } \\
\text { renta }\end{array}$ & 789 & $\begin{array}{c}\text { noviembre/ } \\
\text { diciembre del } \\
2014 \\
\text { (3 semanas) }\end{array}$ & $\begin{array}{c}24 \\
(=1 / 3)\end{array}$ & $\begin{array}{c}349 \\
(=6 \%)\end{array}$ & $\begin{array}{c}\text { Precisión } \\
\text { insuficiente }\end{array}$ \\
\hline
\end{tabular}

Nota: cálculos propios.

*Número de unidades en las que al menos un anuncio ha sido observado. Entre paréntesis, el total de unidades geográficas para cada nivel considerado en toda la ZMVM y, la proporción de cobertura espacial de los anuncios.

Fuente: El Universal (2014), Encuentra tu casa (2014), Metros Cúbicos (2014), Realtor (2014) e Instituto Nacional de Estadística y Geografía -INEGI- (2013). 
Estos datos cuestionan un problema metodológico importante, ya que los valores corresponden a los precios de venta anunciados, pero no a los precios reales de transacción. Tal límite es significativo, pues la diferencia entre ambos valores cambia según los bienes (Kunz et al., 2001); además, todos los bienes anunciados no siempre se venden o se rentan. No obstante, dentro del contexto mexicano, así como en todos los entornos caracterizados por un fraude fiscal importante, es difícil conocer el precio real de la transacción. Por lo mencionado, se concluyó que los precios anunciados quedan como las únicas fuentes accesibles de manera sistemática (Scatigna et al., 2014), siendo también estos datos los que permiten la asimilación del mercado de bienes raíces visible para toda la ZMVM, al nivel preciso de las unidades espaciales del censo - municipios y áreas geoestadísticas básicas (AGEB) - y al nivel de los diferentes tipos de poblamiento.

Después de la limpieza y supresión de los datos atípicos, las bases de datos contaban con más de 20000 anuncios de Internet y más de 2600 anuncios en un periódico impreso, correspondientes a más de 21300 anuncios de venta y casi 1800 anuncios de renta (tabla 1). Según el tipo de anuncios, la cobertura espacial de estas bases varía entre uno de cada tres hasta tres de cada cuatro de los municipios metropolitanos. Para los anuncios de venta en línea, la cobertura espacial sube casi al $40 \%$ de las áreas geoestadísticas básicas, permitiendo así el cruce con los datos sociodemográficos censales.

Del mismo modo, el trabajo de terreno no permitió la constitución de una muestra sistemática, pero sí posibilitó identificar cuáles son las zonas urbanas que no fueron representadas en las bases de datos, y así, en estas zonas, explorar unos mecanismos del mercado de vivienda con mayor profundidad. En particular, se pudo reconstituir los órdenes de magnitud de los precios a partir de las entrevistas con los residentes, y de la consideración de los anuncios publicados en los espacios públicos (Ribardière \& Valette, 2017b).

\section{Una visibilidad y una legibilidad distorsionada de la ciudad y de los rangos de precios}

El primer resultado del análisis espacial de los anuncios inmobiliarios, es la diferencia de visibilidad y legibilidad de la ciudad según el canal de información sobre el mercado de la vivienda (figura 1). La comparación entre los mapas que representan las masas de viviendas, de anuncios impresos y de anuncios en línea permite — dejando de lado la métrica euclidiana-, leer el desajuste entre estas tres geografías. Mientras que las masas demográficas, o más bien, de las viviendas, están principalmente por el pericentro oriental, los anuncios ponen en relieve otras zonas de la metrópoli.

Así pues, en primer lugar, los mapas de localización (anamorfosis) de los anuncios

ANTONINE Ribardière, JEAN-FranÇOIS VALETTE 
Figura 1. Visibilidad de la ciudad por los anuncios inmobiliarios: una distorsión

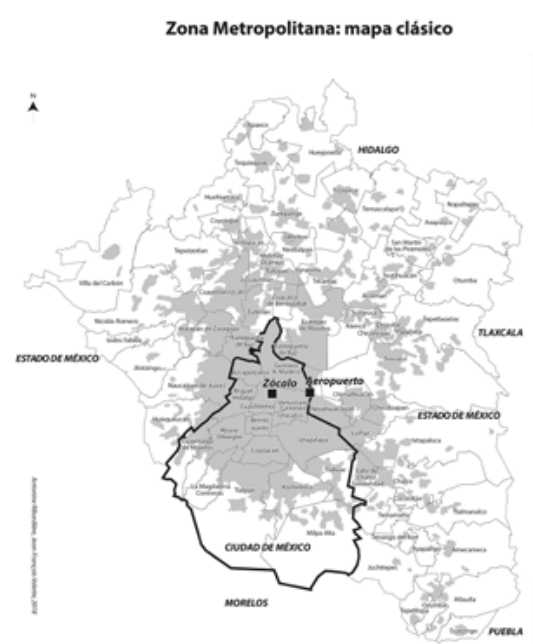
Total de viviendas
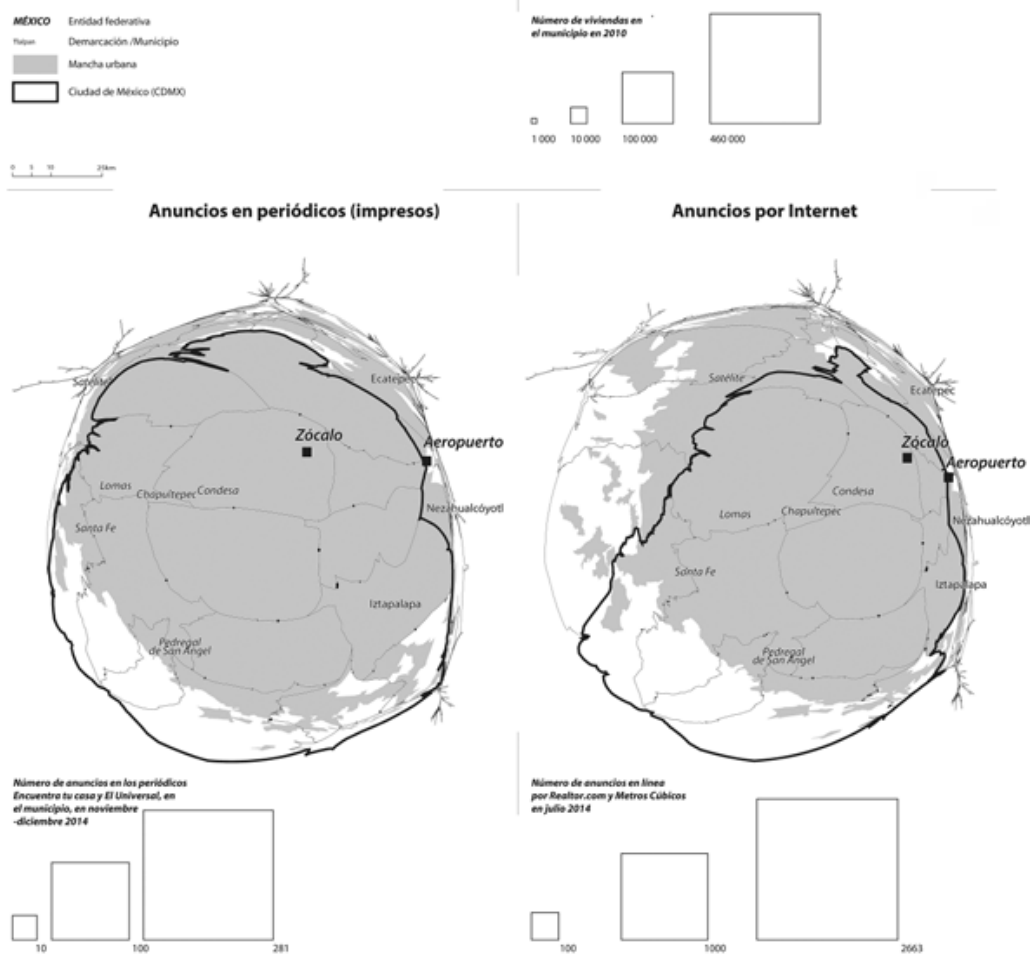

Fuente: El Universal (2014), Encuentra tu casa (2014), Metros Cúbicos (2014), Realtor (2014) e INEGI (2013). 
${ }^{14}$ En el 2015, en estos tres municipios se contó con 1,2 millones de viviendasy 4,6 millones de habitantes.

${ }^{15}$ Las conversiones se hicieron al valor vigente del 30 de julio del 2014, 1 USD = 13,1 MXN $(1 M X N=0,08$ USD).

${ }^{16}$ La superficie de los bienes justifica la distinción entre tipo de bienes: explica $60 \%$ de la varianza de precios anunciados para los departamentos y 40\% para las casas (tipo muy beterogéneo).

\section{tersitarias 44}

en línea permiten una primera lectura del importante desequilibrio este-oeste, que estructura de manera clásica la división social del espacio metropolitano. La imagen de la ciudad en estos mapas magnifica la importancia de los sectores al poniente, de tal manera que se tiene un gran número de anuncios en los municipios occidentales donde las viviendas (en total) para las categorías altas, están sobrerrepresentadas, por ejemplo, en la zona de Santa Fe. Esta concentración se organiza según tres ejes: (i) la zona de las Lomas, desde el centro y Parque de Chapultepec hasta Santa Fe, (ii) desde el pericentro rico de La Condesa hasta el Pedregal de San Ángel, a lo largo de la avenida Insurgentes Sur, y (iii) la zona de Ciudad Satélite al noroeste.

En segundo lugar, los mapas de localización de los anuncios impresos de los periódicos denotan la sobrerrepresentación del centro histórico por este canal más clásico y antiguo, pudiendo encontrar que también aquí, la imagen de la ciudad se distorsiona en comparación con la distribución de las viviendas, poniendo en relieve las zonas habitacionales más densas y populares, pero también una producción nueva creciente.

En tercero y último lugar, cual sea la fuente (impresa o Internet), la cobertura del resto de la ciudad es claramente menor: los espacios donde las viviendas son, en su mayoría, calificables de "populares", en el norte, el este y el sudeste, no aparecen mucho, por ejemplo, en los municipios de
Iztapalapa, Ecatepec y Nezahualcóyotl, aunque estos municipios sean los más poblados del país. ${ }^{14}$

La cuestión de la representatividad de esas bases de datos en comparación con el mercado de la vivienda metropolitano es importante. En la década de los noventa, Kunz et al. (2001) estimaban que los anuncios impresos de los periódicos permitían tener en cuenta un promedio del $40 \%$ de los submercados, de los cuales el $79 \%$ era para los mercados con valores elevados, pero casi nada para los sectores en situación de pobreza, aunque el $38 \%$ de los anuncios estuvieran vinculados con el sector informal. En este trabajo, no fue posible estimar la representatividad de los anuncios impresos y de Internet en relación con el mercado en su conjunto, pero las conclusiones de Kunz todavía nos siguen desafiando en cuanto a la subrepresentación de los segmentos más populares.

Ahora bien, al abordar los resultados de las diferencias de precio, se encuentra que este fortalece el primer resultado, ya que en las bases de datos, particularmente para los anuncios en línea, los bienes caros están sobrerrepresentados (tabla 2). Si se considera los anuncios en línea al nivel de la ZMVM en el 2014, los precios medianos de venta son 6,3 millones de pesos mexicanos (480000 USD $)^{15}$ para una casa, y 3,8 millones de pesos para un departamento (290000 USD), ${ }^{16}$ lo cual se traduce en una cantidad considerable de dinero, que correspondería desde 155 hasta 257 años 
de salario mínimo, o entre 40 y 67 veces el salario mediano anual de un hogar en la ZMVM en el 2015 (Comisión Nacional de los Salarios Mínimos -Cosanami-, 2014; INEGI, 2015). Esta sobrerrepresentación de los precios elevados, significó un sesgo en esta investigación al trabajar con anuncios inmobiliarios disponibles en Internet. ${ }^{17}$

En los anuncios impresos, los valores medianos de venta son cuatro veces más bajos que los de Internet (tabla 3 ). En cuanto a las rentas se tiene el mismo desfase, destacando que mientras una

Tabla 2. Precios medianos según el tipo de bien en venta en línea en la ZMVM en el 2014

\begin{tabular}{|c|c|c|c|c|c|}
\hline \multirow{2}{*}{\multicolumn{2}{|c|}{ Tipo de bien }} & \multicolumn{2}{|c|}{ Casa } & \multicolumn{2}{|c|}{ Departamento } \\
\hline & & \multirow{2}{*}{$\frac{\text { Metros Cúbicos }}{6300000}$} & \multirow{2}{*}{$\begin{array}{l}\text { Realtor } \\
4150000\end{array}$} & \multirow{2}{*}{$\frac{\text { Metros Cúbicos }}{3800000}$} & \multirow{2}{*}{$\begin{array}{l}\text { Realtor } \\
2300000\end{array}$} \\
\hline \multirow{3}{*}{$\begin{array}{l}\text { Precio de los } \\
\text { bienes (en MXN) }\end{array}$} & Precio mediano & & & & \\
\hline & $1 .^{\circ}$ decil & 1650000 & 700000 & 980000 & 550000 \\
\hline & $9 .^{\circ}$ decil & 20670000 & 16979586 & 12350000 & 11680620 \\
\hline \multirow{3}{*}{$\begin{array}{l}\text { Precio del } \\
\text { metro cuadrado } \\
\text { (en MXN) }\end{array}$} & Precio mediano & 17333 & 14700 & 25000 & 23160 \\
\hline & $1 .^{\circ}$ decil & 8690 & 7122 & 13949 & 9184 \\
\hline & $9 .^{\circ}$ decil & 32064 & 28531 & 45772 & 45484 \\
\hline
\end{tabular}

Nota: cálculos propios.

Fuente: Metros Cúbicos (2014) y Realtor (2014).

Tabla 3. Precios medianos según el canal de información en la ZMVM en el 2014

\begin{tabular}{|l|r|r|r|r|r|r|r|r|r|r|}
\hline & \multicolumn{5}{|c|}{ Internet } & \multicolumn{7}{c|}{ Impreso } \\
\cline { 2 - 10 } & $\begin{array}{c}\text { Internet- } \\
\text { Venta }\end{array}$ & $\begin{array}{c}\text { Metros } \\
\text { Cúbicos- } \\
\text { venta }\end{array}$ & $\begin{array}{c}\text { Realtor- } \\
\text { venta }\end{array}$ & $\begin{array}{c}\text { Real- } \\
\text { tor- } \\
\text { renta }\end{array}$ & $\begin{array}{r}\text { Impre- } \\
\text { so-Venta }\end{array}$ & $\begin{array}{c}\text { El } \\
\text { Univer- } \\
\text { sal-venta }\end{array}$ & $\begin{array}{c}\text { Encuentra } \\
\text { tu casa- } \\
\text { venta }\end{array}$ & $\begin{array}{c}\text { Im- } \\
\text { preso- } \\
\text { Renta }\end{array}$ & $\begin{array}{c}\text { E1 Uni- } \\
\text { versal- } \\
\text { renta }\end{array}$ & $\begin{array}{c}\text { Encuen- } \\
\text { tra tu ca- } \\
\text { sa-renta }\end{array}$ \\
\hline $\begin{array}{l}\text { Número } \\
\text { de bienes }\end{array}$ & 20402 & 18015 & 2387 & 545 & 1337 & 289 & 1048 & 1240 & 451 & 789 \\
\hline $\begin{array}{l}\text { Precio } \\
\text { mediano }\end{array}$ & 4800000 & 4950000 & 3800000 & 18500 & 1200000 & 2290000 & 990000 & 6200 & 5500 & 6500 \\
\hline $1 .^{\circ}$ decil & 1100000 & 1200000 & 686200 & 6500 & 350000 & 577000 & 300000 & 2700 & 2000 & 3000 \\
\hline 9. decil & 17550000 & 17580000 & 16920000 & 50976 & 4000000 & 6310000 & 29002000 & 14000 & 15500 & 13500 \\
\hline
\end{tabular}

Nota: cálculos propios en MXN.

Fuente: El Universal (2014), Encuentra tu casa (2014), Metros Cúbicos (2014) y Realtor (2014).

${ }^{17}$ Aumentar el tamaño de la muestra no reduce automáticamente este sesgo, sino todo lo contrario cuando se compararon las dos diferentes fuentes Realtor.com y Metros Cúbicos. 
renta mediana de Internet es $18500 \mathrm{MXN}$ mensuales -21000 MXN para una casa y 16500 MXN para un departamento, es decir, valores muy elevados-, los periódicos proponen rentas alrededor de 6000 MXN mensuales. Esta información es de gran interés y permite calcular la relación precio/alquiler, que aquí sería alrededor de $0,5 \%$, cuyos resultados ya estaban analizados en otros contextos urbanos como Bogotá, para entender la rentabilidad del alquiler en vivienda (Jaramillo \& Cuervo, 2014).

Una vez más, se observa (i) la distinción establecida por canal de información, entre los submercados de la vivienda y las zonas urbanas representadas y, (ii) la visibilidad más importante de la parte alta del mercado inmobiliario habitacional. La segmentación de las lógicas de acceso a la vivienda en la ciudad puede, por una parte, estar aclarada por este medio.

En ese orden de ideas, surgen dos posibles hipótesis. De un lado, el mercado inmobiliario puede tener menor intensidad en las colonias populares que en otras partes de la ciudad (Kunz et al., 2001; Duhau, 2004), pues este no existe en los asentamientos recientes donde el acceso a la vivienda pasa primero por el acceso al suelo, la autoconstrucción y un mercado del suelo más activo que un mercado de los bienes raíces. De otro lado, el mercado inmobiliario "popular" suele usar otros canales: redes sociales, familiares, recomendados de amigos y anuncios en el espacio público. Esa última interpretación podría ser la más indicada, porque permite tener en cuenta con una mayor complejidad, los mecanismos específicos de la producción del espacio habitacional popular.

De hecho, se pueden considerar tres dimensiones importantes del acceso a la vivienda en estas zonas: los anclajes residenciales específicos en colonias populares (Valette, 2019), la importancia de las redes familiares (Parias Durán, 2008; Cosacov, 2017) y, las características económicas y sociales específicas de la trayectoria residencial en zonas populares donde la autoconstrucción es importante. Por esta última dimensión, es posible recordar que las finalidades de la producción popular no son iguales a las observadas para categorías medias y altas. Incluso, en la autoconstrucción el bien no está pensado para venderlo de manera sistemática y el valor que se le asigna puede ser muy importante, debido al trabajo social invertido (Hiernaux-Nicolas, 1991; Gilbert, 2001; Jaramillo, 2008), al peso de las redes sociales y a las organizaciones políticas involucradas en el proceso productivo. En esta producción popular, dentro de las redes familiares, las viviendas o lotes se prestan, regalan, alquilan o venden, según mecanismos de financiación, intercambios $\mathrm{y}$ apoyos de diversas formas, externos al sistema bancario clásico (Schteingart, 1989; Hiernaux-Nicolas, 1991). La morfología espacial de las redes familiares que 
impactan el mercado de la vivienda en estas zonas, está vinculada con las cuestiones de acceso a la propiedad y consolidación del contexto residencial, en términos de inserción en los contextos locales políticos e históricos (Cravino, 2008). Se trata entonces de factores reproductores de micro-divisiones socio-espaciales, ya que se ha observado una intensificación de coexistencia al nivel de la colonia, de la manzana, incluso de la parcela, de situaciones sociales diferenciadas por los anclajes familiares (Valette, 2019).

Fuera del caso mal informado de las zonas populares, las diferentes fuentes de anuncios inmobiliarios, Internet e impreso, permiten la construcción de bases de datos al nivel de la metrópoli. Aunque el número de anuncios pueda ser importante, la densidad de cobertura espacial de estos anuncios destaca fuertes desigualdades urbanas. Las bases describen solamente una parte de la ciudad. No obstante, estos datos selectivos no implican una homogeneidad de los precios, sino por el contrario, la variación es muy amplia. Pero, ¿cómo se inscriben en el espacio urbano estas diferencias de precios?

\section{La variabilidad espacial de los precios}

La variabilidad espacial de los precios, leíble por estos anuncios, permite visualizar un primer enfoque de las desigualdades urbanas en el mercado de la vivienda. Por ejemplo, en el 2014, el precio mediano de una casa en la CDMX era de 7,6 millones de pesos ( 580000 USD), mientras que en el Estado de México, el precio era de 4,8 millones (366000 USD). De igual modo, la diferencia (ratio, relación) entre el precio mediano de una casa en un conjunto habitacional de interés social y una casa en una zona "residencial alta" es de 1 a 8 . El nivel de detalle de las bases de datos recolectadas de Internet permite realizar un análisis a diferentes escalas geográficas.

Primero, a modo general, el análisis de los precios confirma la dicotomía esteoeste de la estructura socio-espacial de la metrópoli (figura 2). La doble lectura municipal del número de bienes por tipo y precio mediano, destaca el peso más importante de los departamentos en el centro, mientras que, para todos los tipos de inmuebles, confirma los precios elevados en el pericentro y en la periferia occidental, en particular, en las demarcaciones Benito Juárez, Miguel Hidalgo, Álvaro Obregón y Cuajimalpa.

Una lectura más detallada pone en relieve particularidades locales en este esquema. En los mapas de escala inframunicipal, las zonas de poblamiento popular están "excluidas" en términos de representación de los precios (figura 3). Se encuentran espacios "vacíos", incluso en la parte poniente de la ciudad. Destacan las desigualdades sociales, a un nivel geográfico muy fino, pues siguen existiendo en esta parte más privilegiada de la metrópoli. Además, 
Figura 2. Precios medianos de las casas y de los departamentos en venta en Metros Cúbicos en julio del 2014, nivel municipal

\section{Casas}

\section{Departamentos}

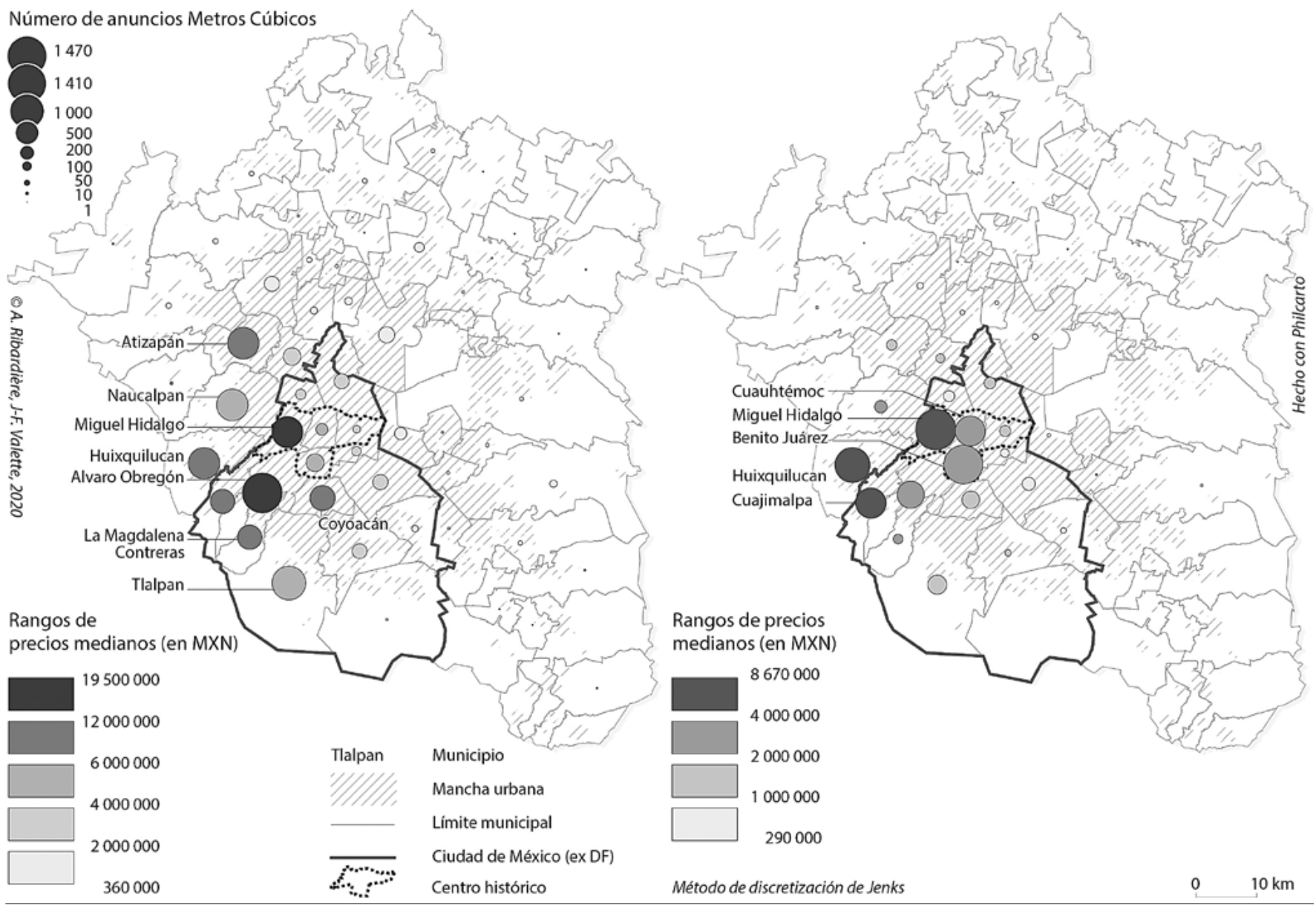

Fuente: Metros Cúbicos (2014) e INEGi (2013).

territarios 44 70 se observan gradientes a lo largo de dos "ejes de riqueza" - Avenida Insurgentes y Paseo de la Reforma-, pero también una clara distinción entre la Ciudad de
México y el Estado de México, donde disminuyen los valores del metro cuadrado. Por último, en la periferia, se identifican los valores más bajos.

ANTONIne Ribardière, JeAN-FranÇOIS VALETTE 
Figura 3. Precio mediano del metro cuadrado de los bienes anunciados en Metros Cúbicos en julio del 2014, nivel AGEB

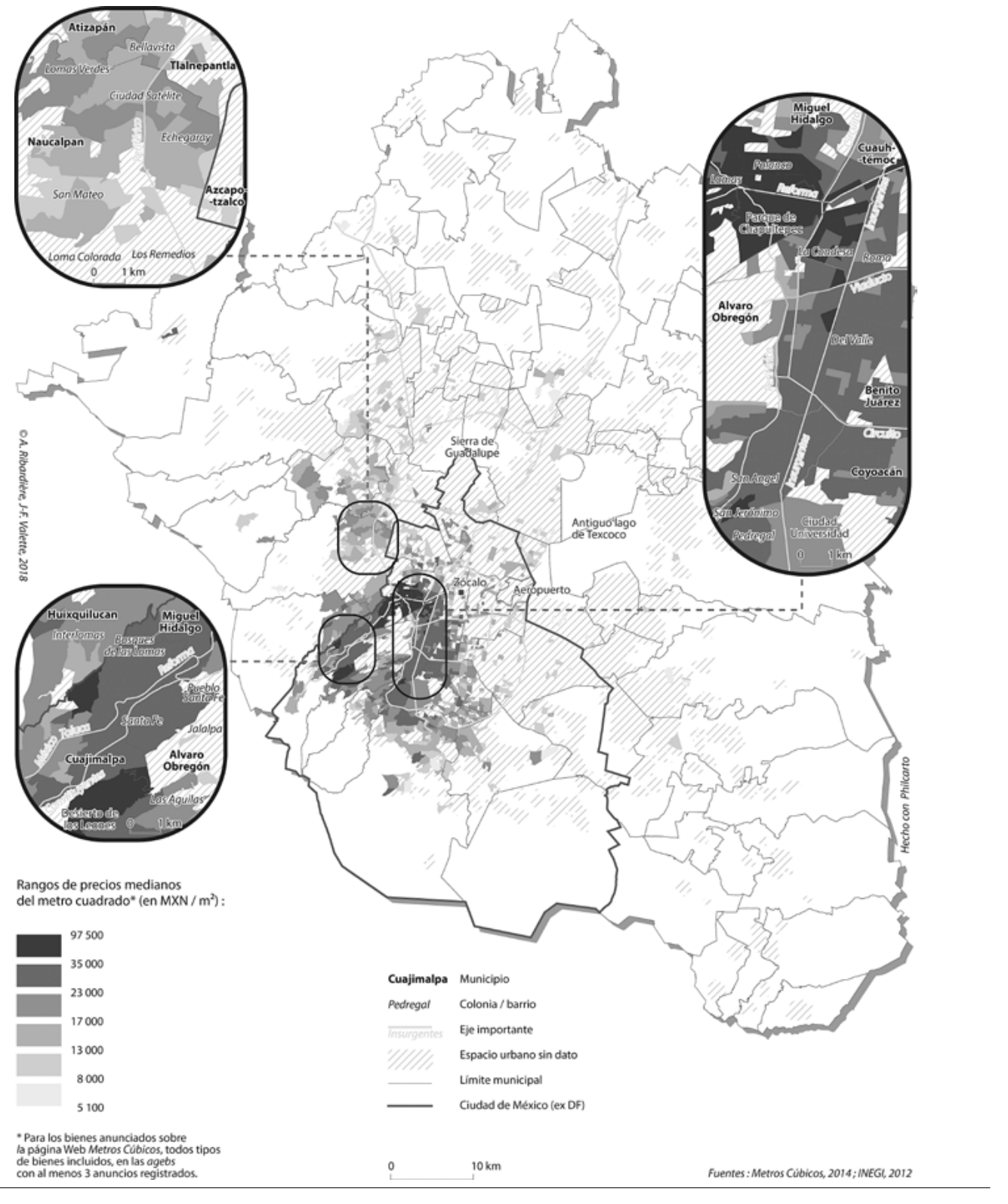

Fuente: Metros Cúbicos (2014) e INEGI (2012). 
${ }^{18}$ Se trata de una tipología de referencia para la Zona Metropolitana del Valle de México, que clasifica las unidades geoestadisticas en tipos de poblamiento definidos por el OCIM. Este trabajo fue coordinado por la UAM-Azcapotzalco en el 2000 (Connolly, 2005). La tipología considera la morfologia de las zonas habitacionales, la antigüedad de la urbanización, su densidad, las condiciones juridicas de la producción y los actores involucrados. Cada AGEB está caracterizada por el tipo predominante. Este trabajo se actualizó $y$ ajustó en el 2010.

\section{territarias 44}

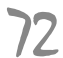

Segundo, un análisis de los precios de venta en línea por "tipos de poblamiento" permite afinar la lectura de la división socio-espacial. Basados en los trabajos del Observatorio Urbano de la Ciudad de México (OCIM), ${ }^{18}$ se distingue la ciudad colonial, la ciudad central, las zonas de vivienda para las categorías altas y medioaltas, los grandes conjuntos habitacionales y las colonias populares (figura 4).

En ese sentido, la repartición de los anuncios por grandes tipos de poblamiento refleja la sobrerrepresentación considerable del espacio residencial superior - apenas más del $1 \%$ del total de las viviendas de la Zona Metropolitana y, más de un anuncio de cada cuatro de la base Internet-, mientras que las colonias populares están subrepresentadas $-45 \%$ del total de las viviendas, pero $15 \%$ de los anuncios-, de igual manera que los conjuntos habitacionales - más de un $25 \%$ de las viviendas frente al $6 \%$ de los anuncios-. En las colonias populares, específicamente, se observa que tienen menos anuncios, pero no están totalmente ausentes de estos. Las zonas que aparecen son las más centrales, consolidadas, y también, en la parte occidental de la ciudad, cercanas de zonas más acomodadas. El $90 \%$ de estos anuncios se ubica en las delegaciones y los municipios pericentrales de la Ciudad de México y del Estado de México, incluyendo zonas populares construidas desde los años 1950. Además, el $70 \%$ de los anuncios en colonias populares se ubica en AGEB pobladas antes de la década de los ochentas. Al contrario, se observa una fuerte subrepresentación de los anuncios en colonias populares recientes: aunque las colonias construidas después de 1990 representen el 6\% de las viviendas en colonias populares de la Zona Metropolitana, en realidad representan menos del $1 \%$ de los anuncios ubicados en este tipo de poblamiento. Los procesos de consolidación, por un lado, y los efectos de contexto metropolitano por el otro, juegan un papel importante para entender la variabilidad espacial de los anuncios y de los precios en estas zonas.

De igual forma, los precios medianos por tipo de poblamiento reflejan muy bien las desigualdades dentro del mercado de la vivienda (tabla 4). Por ejemplo, entre el precio de los bienes en los espacios residenciales altos y el precio de los bienes en los conjuntos habitacionales, la relación es de 1 a 10 .

El precio de las casas es muy elevado en el espacio residencial alto, debido al tamaño de los bienes - los precios del metro cuadrado acercándose a los del centro-. Del mismo modo, el precio de los departamentos sigue siendo muy elevado en estas zonas, ya sea el del valor total anunciado o el del metro cuadrado. El "boleto de entrada" en las zonas acomodadas es muy caro.

El análisis de los precios anunciados también permite ver las diferencias entre las zonas “más populares". Siendo así que el precio en los conjuntos habitacionales es más bajo que el registrado en las colonias populares. Este resultado es interesante ya

ANTONine Ribardière, JeAn-FranÇOIS VALETte 
Figura 4. Tipos de poblamiento en el 2010, repartición de los anuncios y precios de los bienes en el 2014

\begin{tabular}{|c|c|c|c|c|c|}
\hline \multicolumn{2}{|l|}{$\begin{array}{l}\text { Tipo de poblamiento } \\
\text { nivel ageb en el 2010 } \\
\text { (OCIM ajustado) }\end{array}$} & \multirow[t]{2}{*}{$\begin{array}{c}\text { Mapa de ubicación del } \\
\text { tipo de poblamiento } \\
\text { en el } 2010\end{array}$} & \multicolumn{2}{|l|}{$\begin{array}{l}\text { Tipo de poblamiento } \\
\text { nivel ageb en el } 2010 \\
\text { (OCIM ajustado) }\end{array}$} & \multirow[t]{2}{*}{$\begin{array}{c}\text { Mapa de ubicación del } \\
\text { tipo de poblamiento } \\
\text { en el } 2010\end{array}$} \\
\hline $\begin{array}{l}\text { Ciudad colonial } \\
\text { Centro histórico: } \\
\text { zonas urbanizadas en } \\
1793\end{array}$ & $\begin{array}{l}1 \% \text { de las } \\
\text { viviendas } \\
\text { de la ZMVM } \\
\text { 0,3\% de los } \\
\text { anuncios } \\
\text { Mertos } \\
\text { Cubicos } \\
62 \text { anuncios } \\
\begin{array}{l}\text { Metros } \\
\text { Cubicos }\end{array}\end{array}$ & & \begin{tabular}{|l|} 
Conjunto \\
habitacional \\
Zonas urbanizadas por \\
construcción en serie de \\
vivienda multifamiliar \\
o unifamiliar, financia- \\
- da total o parcialmen- \\
-te por los programas \\
de financiamiento \\
habitacional subsidia- \\
-do por el sector \\
público
\end{tabular} & 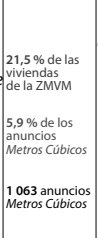 & \\
\hline \begin{tabular}{|l|} 
Ciudad central \\
Expansión de la ciudad \\
central entre 1800 \\
y 1929
\end{tabular} & \begin{tabular}{|l|}
$\begin{array}{l}6,9 \% \text { de las } \\
\text { vivivendas } \\
\text { de la ZMVM }\end{array}$ \\
$16,7 \%$ de los \\
anuncios \\
Metros \\
Cübicos \\
\\
2978 anuncios \\
Metros Cúbicos
\end{tabular} & & $\begin{array}{l}\text { Residencial medio } \\
\text { Fraccionamientos } \\
\text { legales, con infraestruc- } \\
\text {-tura urbana completa, } \\
\text { autorizados en el } \\
\text { marco de la producción } \\
\text { privada, para vender a } \\
\text { las categorias medias y } \\
\text { altas (hogares con } \\
\text { ingresos medios men- } \\
\text {-suales entre } 15 \text { y } 30 \\
\text { salarios minimos de } \\
\text { 2000) }\end{array}$ & $\begin{array}{l}5,6 \% \text { de las } \\
\text { viviendas } \\
\text { de la ZMVM } \\
17,6 \% \text { de los } \\
\text { anuncios } \\
\text { Metros Cúbicos } \\
3146 \text { anuncios } \\
\text { Metros Cúbicos }\end{array}$ & 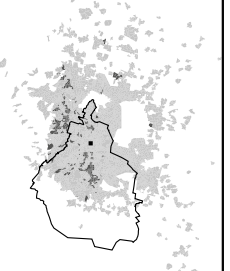 \\
\hline $\begin{array}{l}\text { Casco urbano } \\
\text { Cabeceras, villas, } \\
\text { pueblos mayores } \\
\text { separados del área } \\
\text { urbanizada de la } \\
\text { ciudad en } 1929, \\
\text { posteriormente } \\
\text { absorbidos }\end{array}$ & \begin{tabular}{|l}
$1,8 \%$ de las \\
vivivendas \\
de la ZMVM \\
$1,2 \%$ de los \\
anuncios \\
Metros \\
Cubicos \\
217 anuncios \\
$\begin{array}{l}\text { Metros } \\
\text { Cúbicos }\end{array}$
\end{tabular} & & \begin{tabular}{|l|} 
Residencial alto \\
Fraccionamientos \\
legales, con infraestruc- \\
-tura urbana completa, \\
autorizados en el \\
marco de la producción \\
privada, para vender a \\
las categorias altas, con \\
ingresos superiores a \\
30 veces el salario \\
minimo de 2000 . Los \\
predios son general- \\
-mente superiores \\
$a_{500 \mathrm{~m}^{2}}$
\end{tabular} & $\left\{\begin{array}{l}1,3 \% \text { de las } \\
\text { viviendas } \\
\text { de la ZMVM } \\
27,3 \% \text { de los } \\
\text { anuncios } \\
\text { Metros Cúbicos } \\
4 \\
\text { Metros Cunubicos } \\
\text { Metros }\end{array}\right.$ & 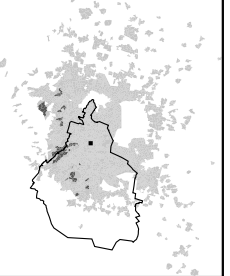 \\
\hline \begin{tabular}{|l|} 
Pueblo conurbado \\
Pueblos menores \\
urbanizados alrededor \\
de las cabeceras \\
después de 1929. \\
Producción urbana \\
generalmente irregular \\
y progresiva.
\end{tabular} & \begin{tabular}{|l}
$7,8 \%$ de las \\
viviendas \\
de la ZMVM \\
$9,8 \%$ de los \\
anuncios \\
Metros \\
Cubicos \\
\\
1756 anuncios \\
Metros Cúbicos
\end{tabular} & & $\begin{array}{l}\text { Pueblo no } \\
\text { conurbano } \\
\text { Espacios urbanizados } \\
\text { en localidades de más } \\
\text { de } 2500 \text { habitantes } \\
\text { dentro de los munici- } \\
\text { - pios de la ZMVM en } \\
\text { 2000, pero que no } \\
\text { están conurbadas. } \\
\text { La urbanización de } \\
\text { estas zonas pasa por } \\
\text { procesos irregulares } \\
\text { generalmente }\end{array}$ & \begin{tabular}{|l}
$6,1 \%$ de las \\
viviendas \\
de la ZMVM \\
$0,8 \%$ de los \\
anuncios \\
Metros Cúbicos \\
\\
135 anuncios \\
Metros Cübicos
\end{tabular} & 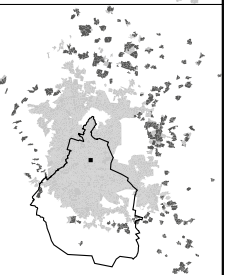 \\
\hline \begin{tabular}{|l|} 
Colonia popular \\
Espacios habitacionales \\
construidos de manera \\
irregular y progresiva. \\
La ocupación antecede \\
la llegada de los servi- \\
-ios. \\
La definición no \\
depende de la situación \\
actual. Incluye una gran \\
heterogeneidad \\
morfológica, social y \\
jurídica
\end{tabular} & 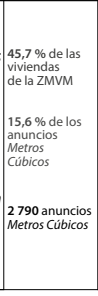 & & $\begin{array}{l}\text { Usos predominante- } \\
\text {-mente no habita- } \\
\text {-cional } \\
\text { No habitacional }\end{array}$ & 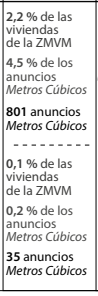 & $05.10 \quad 25 \mathrm{~km}$ \\
\hline
\end{tabular}

Nota: ajustes propios para el 2010.

Fuente: INegi (2012), ocim (2005) y Metros Cúbicos (2014). 
Tabla 4. Precios medianos de los anuncios de venta por tipos de poblamiento según el tipo de bien en julio del 2014

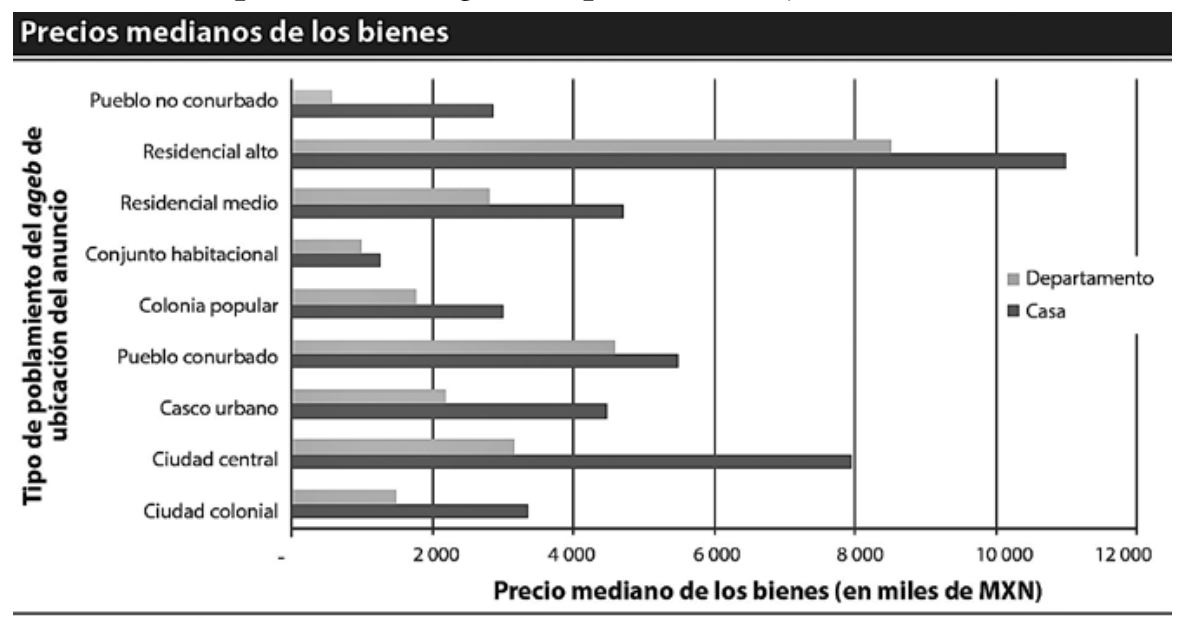

\section{Precios medianos del metro cuadrado}

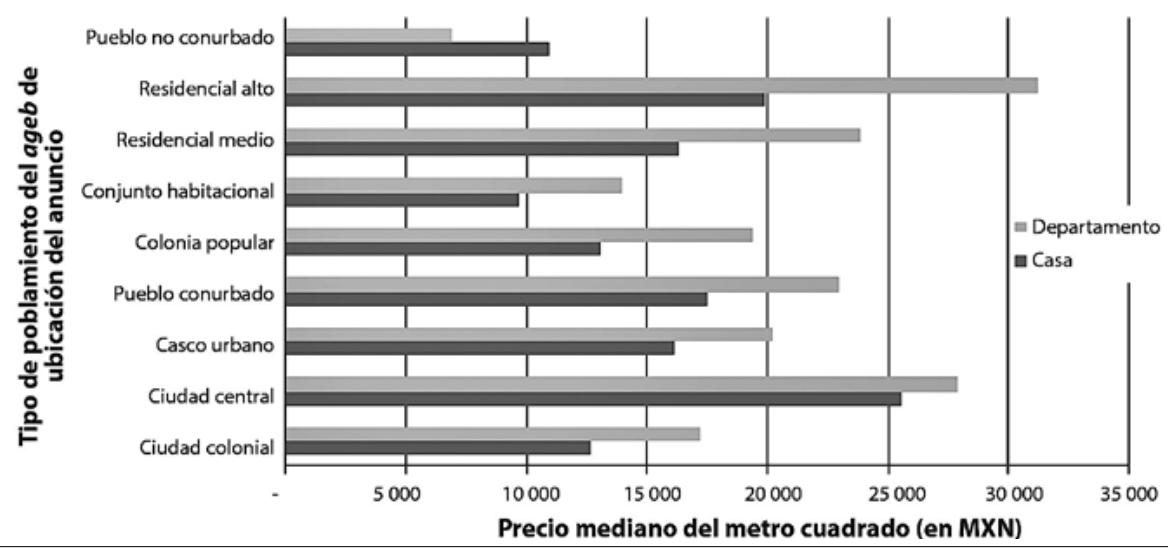

Nota: ajustes y cálculos propios.

Fuente: Metros Cúbicos (2014) y OCıM (2005).

que refleja las trayectorias de consolidación de los asentamientos originalmente informales, $\mathrm{y}$, a su vez, cuestiona el modelo de los recientes conjuntos legales de interés social.
En esa dirección, un análisis de la varianza confirma que las condiciones de producción urbana inciden, por mucho, en la formación de los precios inmobiliarios. La repartición entre diferentes tipos de ANTONine Ribardière, JeAn-FranÇois Valette 
poblamiento explica un $35 \%$ de la varianza de los precios de las casas y un $32 \%$ de los departamentos.

Pero esta explicación no es suficiente, aún se observa una heterogeneidad interna de los precios en cada tipo de poblamiento (tabla 5). En las colonias populares, las diferencias internas ${ }^{19}$ - hasta 13 veces entre el $1 .^{\circ}$ y el $9 .^{\circ}$ decil-, pueden ser explicadas por los diferentes grados de regularización y de verticalización. También, la heterogeneidad en los conjuntos habitacionales es importante y se puede explicar por la estratificación entre los diferentes conjuntos y dentro de estos, entre partes populares y partes más medio-altas, así como por la existencia de trayectorias descendentes de una parte de estas zonas.

Tabla 5. Heterogeneidad de los precios anunciados en Metros Cúbicos por tipos de poblamiento

\begin{tabular}{|c|c|c|c|c|c|c|c|}
\hline \multirow[b]{2}{*}{$\begin{array}{l}\text { Tipo de poblamiento } \\
\text { nivel AGEB en el } 2010 \\
\text { (OCIM ajustado) }\end{array}$} & \multirow[b]{2}{*}{$\begin{array}{l}\text { Número } \\
\text { de } \\
\text { anuncios }\end{array}$} & \multicolumn{3}{|c|}{ Casas } & \multicolumn{3}{|c|}{ Departamentos } \\
\hline & & $\begin{array}{l}\text { Número } \\
\text { de } \\
\text { anuncios }\end{array}$ & $\begin{array}{l}\text { Precios } \\
\text { medianos } \\
\text { de los } \\
\text { bienes }\end{array}$ & $\begin{array}{l}\text { Relación } \\
\text { inter- } \\
\text { decil }\end{array}$ & $\begin{array}{l}\text { Número } \\
\text { de } \\
\text { anuncios }\end{array}$ & $\begin{array}{c}\text { Precios } \\
\text { medianos } \\
\text { de los } \\
\text { bienes }\end{array}$ & $\begin{array}{l}\text { Relación } \\
\text { inter- } \\
\text { decil }\end{array}$ \\
\hline Ciudad colonial & 62 & 8 & 3375000 & & 54 & 1490000 & \\
\hline Ciudad central & 2978 & 805 & 7950000 & 10,6 & 2173 & 3180000 & 6,8 \\
\hline Casco urbano & 217 & 174 & 4475000 & 10,3 & 43 & 2200000 & \\
\hline Pueblo conurbado & 1756 & 1049 & 5500000 & 7,8 & 707 & 4600000 & 10,4 \\
\hline Colonia popular & 2790 & 1605 & 3000000 & 6,9 & 1185 & 1773000 & 13,5 \\
\hline Conjunto habitacional & 1063 & 644 & 1270000 & 12,2 & 419 & 980000 & 6,3 \\
\hline Residencial medio & 3146 & 2066 & 4700000 & 6,4 & 1080 & 2800000 & 5,0 \\
\hline Residencial alto & 4876 & 3139 & 11000000 & 4,8 & 1737 & 8500000 & 4,6 \\
\hline Pueblo no conurbado & 135 & 134 & 2875000 & 21,9 & 1 & 580000 & \\
\hline $\begin{array}{l}\text { Usos } \\
\text { predominantemente } \\
\text { no habitacional }\end{array}$ & 801 & 373 & 9800000 & 17,1 & 428 & 7175000 & 10,2 \\
\hline n. ${ }^{\circ}$ habitacional & 35 & 13 & 10600000 & & 22 & 2974000 & \\
\hline Total & 17859 & 10010 & 6300000 & 12,5 & 7849 & 3800000 & 12,6 \\
\hline
\end{tabular}

Nota: ajustes y cálculos propios para el 2010.

Fuente: OCIM (2005) y Metros Cúbicos (2014).

${ }^{19}$ Calculando la proporción entre el $10 \%$ de los más caros sobre el $10 \%$ de los más baratos. 


\section{La fuerte heterogeneidad socio- espacial de las zonas "populares"}

La aportación indispensable del enfoque de las encuestas empíricas en las colonias populares y en los conjuntos habitacionales, permitió fortalecer la hipótesis precedente de la heterogeneidad socioespacial, particularmente fuerte en los espacios calificados como "populares".

Primero, en las colonias populares donde la urbanización puede estar prohibida - pero con presiones importantes-, el mercado inmobiliario y el mercado del suelo apenas son publicados en periódicos impresos o en Internet, confirmando lo puesto evidenciado en las bases de datos. El mercado funciona principalmente por las redes de conocidos, y así una gran flexibilidad del crédito. Además de las redes sociales, se observa el papel importante de los anuncios informales en el espacio público. El mercado de terrenos que no se veía en las bases, parece muy dinámico, se observan ventas importantes y organizadas. Por último, el mercado de la renta - cuartos dentro de las casas o departamentos en inmuebles - es muy visible en el espacio público, aunque casi no aparezca por otros canales (Ribardière \& Valette, 2017b).

Segundo, todavía en las colonias populares, el análisis de una muestra de precios destaca desigualdades muy fuertes en una misma zona (tabla 6). Así se constataron diferencias importantes entre las colonias

Tabla 6. Rangos de precios de venta del metro cuadrado en asentamientos irregulares de la periferia en el 2010 y el 2014

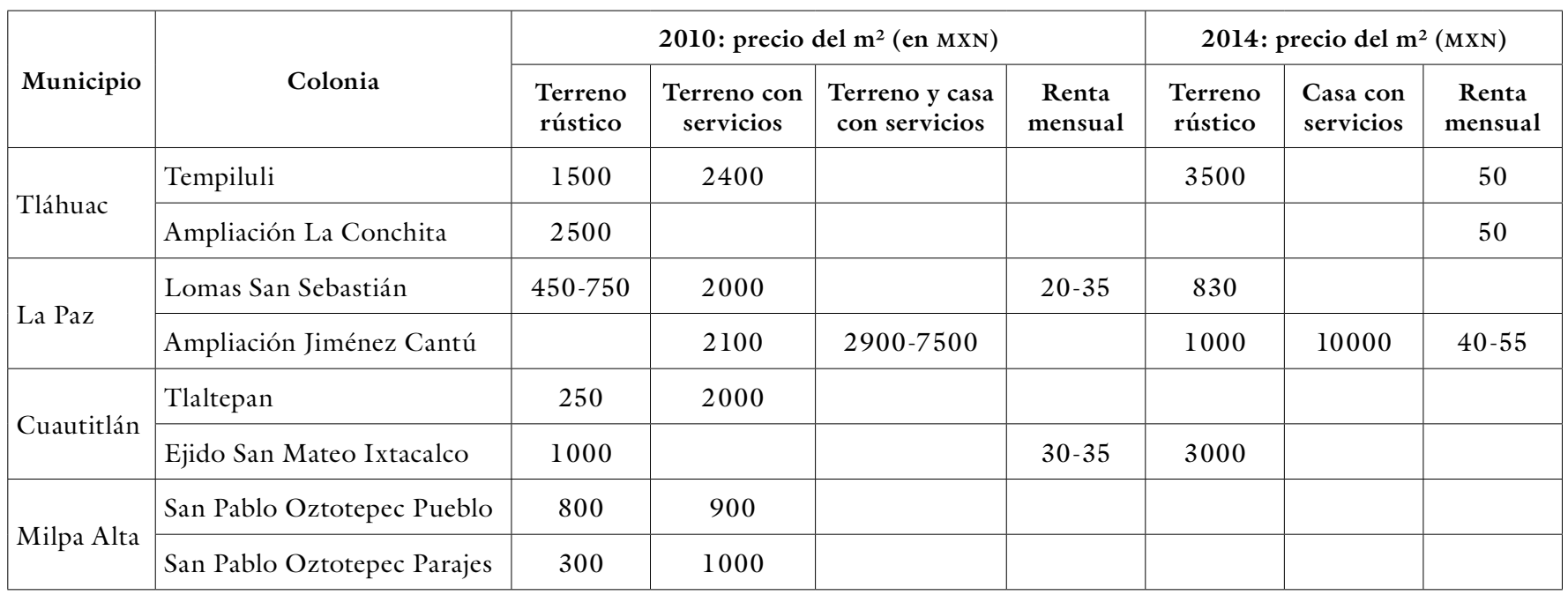

Fuente: elaboración propia (2014). 
estudiadas según el contexto local. El precio del suelo urbano varía de forma clásica, según cinco parámetros: (i) la localización, (ii) los servicios disponibles - mínimo de vías públicas, luz y agua-, (iii) el "grado de desigualdad" — contexto político-administrativo de la zona, en términos de plan de desarrollo urbano y de perspectivas de regularización-, (iv) la presión-especulación en la zona y (v) la movilización política en torno a transacciones informales - grupos de presión que pueden hacer disminuir los costos-.

Tercero, en los conjuntos habitacionales legales, el dinamismo del mercado inmobiliario parece muy fuerte, en comparación con la lectura de estas zonas permitida por los anuncios impresos y en Internet. Los precios observados en el terreno son menores que los precios analizados a través de las bases de datos - incluso tres veces menos que la mediana de la base Internet-. Tales resultados exploratorios concordaron con una tendencia al bajo valor (para la reventa) de las viviendas de estos conjuntos, debido a la baja calidad de la construcción. También reflejan que además de la diferencia estructural según el canal de información, los anuncios en línea tienen tal vez como objetivo una gama alta de este tipo de viviendas.

A fin de cuentas, si se compara la compra de una casa antigua en una colonia popular y la compra (por reventa) de una vivienda de interés social, el precio del bien en colonia popular puede ser superior, considerando las superficies y la calidad de la construcción. Esta constatación corrobora los resultados obtenidos a partir de las bases de datos. Ahora bien, al comparar la compra de una parcela, la autoconstrucción y la regularización en una colonia popular, con la compra de una casa nueva, llave en mano en un conjunto habitacional, la relación es inversa, por lo que la autoconstrucción sigue siendo la oferta de vivienda la más económica.

\section{Conclusión}

En resumen, las bases de datos sobre los precios inmobiliarios anunciados (impresos y en línea), constituyen una fuente bastante interesante. Los anuncios permiten seguir el mercado legal en la ciudad y pueden estar localizados en diferentes lugares geográficos. No obstante, estas fuentes son insuficientes para abarcar el conjunto de los segmentos del mercado inmobiliario de la metrópoli, sobre todo para los sectores "populares". Las colonias populares y los conjuntos habitacionales están presentes en las bases, pero solo en algunos segmentos - en términos cualitativos y geográficos- Cuanto más baratas son las viviendas recientes en los límites de la ciudad, resulta menos fácil acceder a ellas a través de los anuncios "oficiales". Las fuentes que permiten acceder a estos segmentos son imposibles de sistematizar al nivel de una ciudad como CDMX, por lo que el trabajo de terreno sigue siendo indispensable. 
En primera instancia, la magnitud de las diferencias de precios observadas destaca el alcance de las desigualdades económicas. Estas desigualdades no solo pueden tenerse en cuenta con los indicadores sociodemográficos. Las medidas en términos de condiciones de vida, por ejemplo, no muestran explícitamente qué partes de la ciudad son completamente inaccesibles para la mayoría de la población. Sin embargo, las considerables diferencias de precios observadas a nivel metropolitano no deben sugerir la imagen de submercados de viviendas homogéneas. Por el contrario, el análisis de los precios dentro de los diferentes tipos de poblamiento muestra la heterogeneidad que existe dentro de cada categoría.

En segunda instancia, los precios influyen en caracterizar los contextos habitacionales, así como las lógicas de reproducción de las desigualdades sociales en el espacio urbano, en términos (i) de acceso a la vivienda, (ii) de valores del suelo y del techo y (iii) de valores de "opinión" descritos por Halbwachs (1908) en cuanto a los bienes inmobiliarios. De hecho, la comprensión de la geografía de los precios incita a distinguir entre, desde una perspectiva, las diferencias de costos como mero reflejo de las desigualdades y, desde otra, la reproducción de estas desigualdades por los procesos de movilidad residencial de los hogares - movilidades vinculadas con el mercado inmobiliario, pero que también contribuyen a reproducir las desigualdades de precios- En ese marco, tres pistas de reflexión parecen interesantes.

Primero, dicha reproducción tiene que ser entendida desde el punto de vista de la construcción de estrategias residenciales de los individuos y de los hogares al momento del cambio de residencia. Estas estrategias están definidas por las limitaciones económicas, pero también por la lógica y los hábitos familiares, incluido el acceso a la información.

Segundo, a una escala más agregada, el análisis de las movilidades residenciales y las cadenas de ocupación de viviendas, tal como se describe en la teoría del filtrado residencial, permite entender la reproducción de los procesos y resultados de división socio-espacial habitacional (Valette, 2019). La información de los precios dada por los anuncios, impacta las construcciones de los precios en las zonas en proceso de valorización y participa en esa misma valorización efectiva y simbólica. El incremento del valor de las propiedades en el centro, contribuye a la exclusión de los hogares sin los recursos económicos suficientes para permanecer en la centralidad. Así mismo, la movilidad de las personas en situación de pobreza sigue un esquema centrífugo, estructurado por los precios más accesibles del suelo y las políticas de apoyo a la vivienda social en las periferias este y norte. Al hacer un filtrado entre los dos, se reestructura la composición social del pericentro de manera compleja. De forma que se vuelve posible la lectura de las 
características clásicas de la división social de la ciudad, reforzando la conexión entre precio de la vivienda, movilidad residencial y repartición de los grupos sociales en la metrópoli. Esta división nutre la gentrificación del centro, una polarización reforzada entre un centro adinerado y una periferia oriental de bajos recursos, y también la constitución de una "clase media" importante en el norte (Valette, por publicar). El aumento de los precios - que necesitaría una vigilancia diacrónica rigurosa- parece muy sensible en todas las zonas de la metrópoli, aunque de hecho, no significaría un proceso generalizado de gentrificación. Este fenómeno bien estudiado en las zonas centrales (Delgadillo, 2016b; Díaz, 2014; Salinas, 2013) da resultados, en términos de cambio de poblamiento, que deben diferenciarse de un proceso masivo de aumento de precios en todos los sectores populares en general, pero tiene un impacto global al nivel de la ciudad, como un efecto dominó sobre los valores del suelo.

Tercero, existe un vínculo entre la producción mercantil y el mercado de reventa, aunque este sea complejo y plural. Además del análisis de las movilidades residenciales y las cadenas de desocupación de las viviendas en el proceso de filtrado abordado, el mercado de las viviendas usadas en México tuvo un gran aumento en el otorgamiento de créditos hipotecarios desde el 2010, cuando al mismo tiempo, para la vivienda nueva disminuyeron. El proceso de financiarización puede implicar dos dimensiones sobre la construcción de los precios: el primer aspecto es el valor de la vivienda usada a la reventa, siendo más bajo a la reventa de manera general, la mercantilización y la financiarización del espacio habitacional, se ancla mucho más en su producción nueva que en su circulación secundaria. Por eso, es lo que revela la producción dentro del proceso de desarrollo urbano de acuerdo con la forma de conjuntos habitacionales para clases medias en la periferia. De un lado se tiene la gentrificación y valorización de los espacios céntricos y pericéntricos, que producen nuevos espacios habitacionales para las clases altas; y de otro, son característicos del papel jugado por empresas constructoras vinculadas con grupos bancarios en la valorización de los espacios urbanos. Esta valorización de la vivienda acentúa la división social del espacio habitacional. El segundo aspecto, es que fuera de la vivienda nueva, la circulación de la vivienda usada para clases medias y bajas se entiende con la bancarización del acceso a la vivienda, incluida la usada. Los hogares incapaces de comprar en la producción nueva, son dependientes de mecanismos bancarios con créditos hipotecarios que siguen reproduciendo desigualdades, sea por el endeudamiento de amplias partes de la clase media y baja, o, por la exclusión de las categorías sociales de escasos recursos del mercado formal.

De esta forma, los precios permiten identificar de manera relevante las lógicas de la producción urbana, caracterizada 
por la especulación y la presión sobre los espacios habitacionales populares debido a la valorización cada vez más fuerte desde los espacios céntricos, pero sobre todo, dentro del proceso de financiarización de la producción de viviendas para la clase media y baja.

\section{Referencias}

Abramo, P. (2003). La teoría económica de la favela: cuatro notas sobre la localización residencial de los pobres y el mercado inmobiliario informal. Revista Ciudad y Territorio: Estudios territoriales, 35(136-137), 273-294. https://recyt.fecyt.es/index.php/ CyTET/article/view/75391

Abramo, P. (2008). El mercado del suelo informal en favelas y la movilidad residencial de los pobres en las grandes metrópolis: un objeto de estudio para América Latina. Territorios, (18-19), 55-73. https://www.redalyc.org/ pdf/357/35711626003.pdf

Abramo, P. (Coord.). (2009). Favela e mercado informal: a nova porta de entrada dos pobres nas cidades brasileiras. ANTAC. https://issuu.com/habitare/ docs/colecao_10

Aveline-Dubach, N. (2008). Immobilier, la mondialisation, l'Asie, la bulle. CNRSÉditions.

Azuela, A., \& Tomas, F. (1997). El acceso de los pobres al suelo urbano. UNAM.

Casanova, L., Boulay, G., Gérard, Y., \& Yahi, L. (2017). Deux bases de données, aucune référence de prix: Comment observer les prix immobiliers en France avec Dvf et Perval? Revue d'Économie Régionale \& Urbaine, 4(4), 711-730. https://doi. org/10.3917/reru.174.0711

Cetre, M. (2015). La financiarización como una de las transformaciones de las ciudades latinoamericanas. Revista Republicana, (18), 113-133. http:// ojs.urepublicana.edu.co/index.php/ revistarepublicana/article/view/210 Comisión Nacional de los Salarios Mínimos (Conasami). (2014, 14 de enero). Nuevos salarios minimos 2014, por área geográfica generales y profesionales. Secretaría del Trabajo y Previsión Social. http://www.conasami.gob.mx/ nvos_sal_2014.html

Connolly, P. (2005). Tipos de poblamiento en la Ciudad de México, reporte de investigación. Serie Metodología, OCIM-SIG, UAM-A.

Connolly, P. (2008). Urbanizaciones irregulares como forma dominante de ciudad. En C. Iracheta \& C. S. Medina, Irregularidad y suelo urbano: ¿Cómo incidir en las prácticas y hacia dirigir las politicas públicas en México para enfrentar dicho fenómeno? (pp. 143169). El Colegio Mexiquense.

Cosacov, N. (2017). El papel de la familia en la inscripción territorial. Exploraciones a partir de un estudio de hogares de clase media en el barrio de Caballito, Buenos Aires. Población es Sociedades, 
24(1), 35-65. https://dialnet.unirioja. es/servlet/articulo? codigo $=6065995$

Coulomb, R. (1988). Logement locatif et dynamique de l'habitat dans la ville de Mexico. Geocarrefour, 63(1), 9-25. https://doi.org/10.3406/geoca.1988.3353

Cravino, M. C. (2008). Relaciones entre el mercado inmobiliario informal y las redes sociales en asentamientos informales del área metropolitana de Buenos Aires. Territorios, (18-19), 129-145. https://revistas.urosario. edu.co/index.php/territorios/article/ view/830

Cuervo, N. (2017). L'inertie et les changements urbains au prisme des prix $d u$ logement. Bogotá, 1970-2012. Université Paris-Est. https://tel.archives-ouvertes.fr/tel-01557192

David, L., \& Halbert, L. (2013). Finance capital, actor-network theory and the struggle over calculative agencies in the business property markets of Mexico City metropolitan region. Regional Studies, 48(3), 516-529. https://doi.or $\mathrm{g} / 10.1080 / 00343404.2012 .756581$

Delgadillo, V. (2016a). Financiarización y mercantilización del desarrollo urbano en escala planetaria. Entrevista a Carlos A. de Mattos. Andamios, 13(32), 213-343. http://www.scielo.org. $\mathrm{mx} /$ scielo.php ?pid $=\mathrm{S} 1870$ $00632016000300213 \& \mathrm{script}=\mathrm{sci}$ arttext

Delgadillo, V. (2016b). Ciudad de México, quince años de desarrollo urbano intensivo: la gentrificación percibida. Revista INVI, 31(88), 101129. https://doi.org/10.4067/S071883582016000300004

Díaz, J. (2014). La gentrification négociée. Anciennes frontières et nouveaux fronts dans le centre historique de Mexico (Thèse de doctorat de géographie). Université Toulouse 2 Le Mirail.

Duhau, E. (2004). Politiques du logement et intégration au Mexique: de la promotion publique à la promotion immobilière privée. Cabier des Amériques Latines, (44), 119-136. https://doi. org/10.4000/cal.7434

Eibenschutz, R., \& Benlliure, P. (2009). Costos y beneficios de los mercados formal e informal de suelo para familias con bajos ingresos. Análisis de ocho ciudades. SEDESOL \& UAM-X.

Gilbert, A. (2001). ¿ Una casa es para siempre? Movilidad residencial y propiedad de la vivienda en los asentamientos autoproducidos. Revista Territorios, (6), 51-73. https://revistas.urosario. edu.co/index.php/territorios/article/ view/5652

Girón, A., \& Chapoy, A. (2009). Financiarización y titulización: un momento Minsky. Economía UNAM, 6(16), 4456. http://www.scielo.org.mx/scielo. php ? script $=$ sci_arttext $\&$ pid $=S 1665$ 952X2009000100003

Global Property Guide. (2015). Gross rental yields in Mexico moderately good. Global Property Guide. [Consultado en octubre del 2018]. http://www. territarias 44 81 
globalpropertyguide.com/Latin-America/Mexico/Rental-Yields.

Halbwachs, M. (1908). La politique foncière des municipalités. Brochure de la librairie du Parti socialiste (n. $\left.{ }^{\circ} 3\right)$. Les cahiers du socialiste.

Hiernaux-Nicolas, D. (1991). La autoconstrucción de la vivienda en el Área Metropolitana de la Ciudad de México. Revista Interpretaciones, (1), 58-73.

Instituto Nacional de Estadística y Geografía (INEGI). (2013). Resultados del censo de población y vivienda 2010. INEGI. https://www.inegi.org.mx/ programas/ccpv/2010/

Instituto Nacional de Estadística y Geografía (INEGI). (2015). Encuesta intercensal 2015. INEGI. https://www.inegi. org.mx/programas/intercensal/2015/

Iracheta, A., \& Medina, S. (2008). Irregularidad y suelo urbano: ¿Cómo incidir en las prácticas y hacia dirigir las políticas públicas en México para enfrentar dicho fenómeno? (ponencia). Memorias del II Congreso Nacional del Suelo Urbano. El Colegio Mexiquense.

Isunza Vizuet, G., \& Méndez Bahena, B. (2011). Desarrollo inmobiliario y gobiernos locales en la periferia de la Ciudad de México. EURE, 37(111), 107-129. http://dx.doi.org/10.4067/ S0250-71612011000200005

Jaramillo, S. (2008). Reflexiones sobre la "informalidad" fundiaria como peculiaridad de los mercados del suelo en las ciudades de América Latina. Territorios, (18-19), 11-55. https:// revistas.urosario.edu.co/index.php/ territorios/article/view/826

Jaramillo, S., \& Cuervo, N. (2014). Precios inmobiliarios de vivienda en Bogotá 1970-2013. Documentos CEDE. Universidad de los Andes. https:// economia.uniandes.edu.co/components/com_booklibrary/ebooks/dcede2014-18.pdf

Kunz Balaños, I., González Sánchez, J., \& Valverde, C. (2001). El Mercado inmobiliario habitacional de la Ciudad de México. Plaza y Valdés.

Lara, J. A., Estrada, G., Zentella, J. C., \& Guevara, A. (2017). Los costos de la expansión urbana: aproximación a partir de un modelo de precios hedónicos en la Zona Metropolitana del Valle de México. Estudios Demográficos y Urbanos, 32(1), 37-63. http://192.203.177.185/bitstream/ handle/ibero/1499/GSA_Art_02. pdf? sequence $=1$ \& is Allowed $=y$

Le Goix, R., \& Vesselinov, E. (2013). Gated Communities and House Prices: Suburban Change in Southern California, 1980-2008. International Journal of Urban and Regional Research, 37(6), 2129-2151. https://doi.org/10.1111/ j.1468-2427.2012.01139.x

Le Goix, R., Boulay, G., Callen, D., Derambure-Dutel, F., Reys, A., Giraud T., \& Cura, R. (2016, 17-18 mars). Marchés immobiliers ET zones critiques: une analyse du changement social en relation avec la dynamique des valeurs immobilières (ponencia). 
Actes $d u$ colloque $d u$ CIST-Collège International des Sciences du Territoire" En quête de territoire(s)? Looking for territories? (pp. 268-276). Grenoble, Francia.

Libertun, N. (2018). Why there? Developers' rationale for building social housing in the urban periphery in Latin America. Cities, 72, 411-420. https:// doi.org/10.1016/j.cities.2017.10.006

Libertun, N., \& Guerrero, R. (2017). ¿Cuánto cuesta la densificación? La relación entre la densidad y el costo de proveer servicios públicos municipales en Brasil, Chile, Ecuador y México. Revista EURE-Revista De Estudios Urbano Regionales, 43(130), 235-267. https://doi.org/10.4067/ s0250-71612017000300235

De Mattos, C. (2016). Financiarización, valorización inmobiliaria del capital y mercantilización de la metamorfosis urbana. Sociologias, 18(42), 24-52. https://doi.org/10.1590/15174522018004202

Parias Durán, A. (2008). El mercado de arrendamiento en los barrios informales en Bogotá, un mercado estructural. Revista Territorios, (18-19), 75-101. https://revistas.urosario.edu.co/index.php/territorios/article/view/828

Perló, M. (2002). Análisis del comportamiento del mercado inmobiliario habitacional en la zona centro de la Ciudad de México. En A. Sánchez Almanza (Coord.), Financiamiento para el desarrollo urbano regional en México: necesidades y perspectiva. UNAM.

Perló, M., \& Kunz, I. (1994). Investigación del mercado de ofertas para el suelo, venta y rentas de inmuebles. Secretaría de Planeación y Evaluación del Departamento del D. F.

Ribardière, A., \& Valette, J. F. (2017a). Geography of real estate prices in Mexico City: Variability and heterogeneity of values recorded in online advertisements. Cybergeo: European Journal of Geography, 814. https://doi. org/10.4000/cybergeo.28529

Ribardière, A., \& Valette, J. F. (2017b). Accéder au foncier et à l'immobilier à Mexico. La diversité des marchés vue depuis l'espace public. EchoGéo, (40). https://doi.org/10.4000/echogeo.14951

Salinas, L. (2013). Gentrificación en la ciudad latinoamericana. El caso de Buenos Aires y Ciudad de México. GeoGraphos: Revista Digital para Estudiantes de Geografía y Ciencias Sociales, 4(44), 281-304.

Scatigna, M., Szemere, R., \& Tsatsaronis, K. (2014, septiembre). Statistiques des prix de l'immobilier résidentiel dans le monde. Rapport trimestriel BRI. https://www.bis.org/publ/qtrpdf/r_ qt1409h_fr.pdf

Schteingart, M. (1989). Los productores del espacio habitable: estado, empresa y sociedad en la Ciudad de México. Colegio de México, Centro de Estudios Demográficos y de Desarrollo Urbano. territarias 44

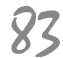


Sociedad Hipotecaria Federal (SHF). (2014). Indice SHF de precios de la vivienda en México 2014. https://www.gob. $\mathrm{mx} /$ shf/documentos/indice-shf-deprecios-de-la-vivienda-en-mexico-2014

Sobrino, J. (2014). Housing Prices and Submarkets in Mexico City: A Hedonic Assessment. Estudios Económicos, 29(1), 57-84. https://www.jstor.org/ stable/24725745

Streule, M., Karaman, O., Sawyer, L., \& Schmid, C. (2020). Popular urbanization: Conceptualizing Urbanization Processes Beyond Informality. International Journal of Urban and Regional Research. https://doi. org/10.1111/1468-2427.12872

Terrazas, O. (1996). Las mercancias inmobiliarias. Estudios Urbanos, UMA-A.

Valdivia, R. (2014). Modelo de precios hedónicos para la vivienda nueva en la
ZMVM. Estudio de caso en la Zona metropolitana del Valle de México. Publicia. Valette, J. F. (2019). Mobilités et ancrages résidentiels dans les colonies populaires de Mexico: une dimension de la maturation des périphéries. Annales de Géographie, 725(1), 64-99. https:// doi.org/10.3917/ag.725.0064

Valette, J. F. (por publicar). Movilidad residencial y anclajes en la Zona Metropolitana del Valle de México: una lectura de la división socio-espacial en las colonias populares periféricas.

Ward, P. M., Jiménez, E. R., Di Virgilio, M., \& Camargo, A. (2015). Politicas de vivienda en ciudades latinoamericanas. Una nueva generación de estrategias y enfoques para 2016 ONU-Hábitat III. Universidad del Rosario. 